\title{
The Italian network on LCA
}

\author{
Francesca Cappellaro • Simona Scalbi • Paolo Masoni
}

Published online: 22 October 2008

(C) Springer-Verlag 2008

\section{Introduction}

Life cycle assessment (LCA) studies are growing in number, first of all, through the impulse deriving from the European policies for environment, energy, resources and waste. The European Commission now considers life cycle approach as an efficient method for the identification of the most relevant burdens and for establishing the improving strategies, and it has also been implemented (sometime also made compulsory) in the most recent communications and directives. ${ }^{1}$

In parallel to the enlargement of the application fields, as far as R\&D is concerned, several activities are in progress (such as the UNEP-SETAC LC1, ${ }^{2}$ the European Platform

\footnotetext{
${ }^{1}$ Examples for the integration of Life Cycle Thinking in European polices are: Directive on the Eco-design requirements for Energyusing Products (EuP), Thematic Strategies on the Sustainable Use of Natural Resources and on Waste Prevention and Recycling, and, the upcoming, Sustainable Consumption and Production (SCP) Action Plan.

${ }^{2} \mathrm{http} / /$ www.uneptie.org/pc/sustain/lcinitiative/

Responsible editor: Walter Klöpffer

F. Cappellaro $\cdot$ S. Scalbi $\cdot$ P. Masoni $(\bowtie)$

Bologna Research Centre,

ENEA-Italian National Agency for New Technologies,

Energy and the Environment,

Via Martiri Monte Sole 4,

40129 Bologna, Italy

e-mail: paolo.masoni@bologna.enea.it

F. Cappellaro

e-mail: francesca.cappellaro@bologna.enea.it

S. Scalbi

e-mail: simona.scalbi@bologna.enea.it
}

on $\mathrm{LCA},{ }^{3}$ etc.) with the aim of improving reliability and usability of LCA by means of the development of reference databases, of simple and specialised software tools, technical guidance and consensus on impact assessment methods. The $R \& D$ is also finalised to increase the significance of the results in terms of spatial and time aspects, of the three pillars of sustainability and of applicability to macro-and meso-systems. Described shortly in the perspective above, the European R\&D lines for the sustainability are increasingly encouraging assessment methods based on a life cycle approach and fostering the networking of structures working in this field (Curran and Notten 2006).

In this context, the Italian situation presents some delays, with a minor sensibility and capacity of both private and public structures to utilise the contribution LCA can give to more efficient sustainability policies and to better react to the new regulatory framework. In addition, the number of competencies and structures active in the LCA field is narrower in comparison with other countries. Moreover, what were missing are places and modes for a mutual and not episodic inter-exchange of experiences and specific initiatives both in the R\&D and application fields.

Starting from this consideration, the 'LCA and Ecodesign' team of ENEA promoted a workshop of public and private structure in October 2006 that are active in the field of LCA in Italy and more generally on life cycle approach. Goals of the workshop were, for one end, to focus on the most relevant research and application issues in relation with the 7FP of the EU and the national policies on energy, environment and industry and, for the other end, to promote an efficient network.

\footnotetext{
${ }^{3}$ http://lca.jrc.ec.europa.eu/EPLCA/index.htm
} 
The main result of this workshop was the establishment of a national LCA network among all the organisations which work and are interested in LCA.

\section{Mission and activities}

The LCA Italian Network is an initiative aimed at promoting the dissemination of LCA methodology through the creation of a network to exchange knowledge, information, methods and good practices on LCA state of the art and perspectives in Italy.

The main LCA Italian network objectives are:

- promoting knowledge sharing on methods, good practices and resources on LCA studies in Italy;

- favouring LCA so as to make it known as an established and accredited technique at the national level;

- encouraging the creation of a network among the several sectoral experts for accomplishing national and international projects.

The initiative is promoted and co-ordinated by ENEA (Italian National Agency for New Technologies, Energy and the Environment), with the support of the Ministry of Environment.

The network involves the main Italian experts of LCA systems (universities and research centres, consultants, companies, national and regional agencies, etc.). The network has an informal nature based on voluntary contribution of participants. A website has been implemented (www.reteitalianalca.it), and it provides information services (website, newsletter, mailing list), working groups, annual meetings and annual surveys on the Italian LCA situation.

The website has demonstrated until now to be a useful tool to enable discussions, present and inform on LCA studies and on research in Italy. The website consists of the following sections:

- Presentation of LCA Italian network

- Archive of newsletter and proceedings of annual workshops

- Mapping of LCA: surveys and data on LCA groups and activities in Italy

- Working groups: documentation and specific information on several sectors

- Events and news where opportunities and promoted initiatives in the LCA field are shown

A mailing list is active for the exchange and dissemination of information among LCA Italian Network members. The list is designed to allow users to get in touch using the e-mail service managed by ENEA Bologna Research Centre. Currently, there are about 300 persons registered,

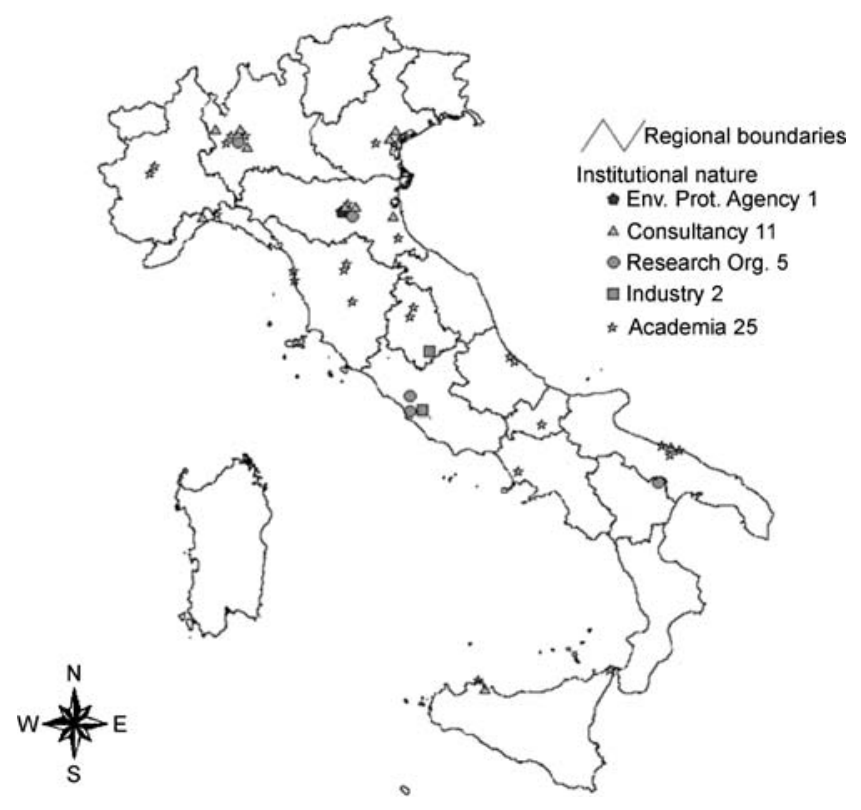

Fig. 1 Geographical distribution of LCA teams, specifying their institutional nature in Italy

coming from more than 40 Italian provinces and distributed over 17 Italian regions. All registrants also receive a three monthly newsletter.

\section{Mapping Italian LCA teams and activities}

In order to provide more detailed information on the LCA Italian situation, a map of the teams active in Italy was developed based on a survey of nature, dimension of the teams, type of activity, application fields, development perspectives, etc. A questionnaire was available on line at the LCA network website. Presently, 44 questionnaires

Table 1 Specialisation area of the LCA teams in Italy

\begin{tabular}{lc}
\hline & Number of applications \\
\hline LCA applications & \\
LCA studies & 42 \\
Certification support & 22 \\
Methodology development & 12 \\
Tool development & 11 \\
IPP tools & \\
Ecodesign & 20 \\
EMS & 17 \\
Life cycle approach model or methods & 17 \\
Guidelines & 8 \\
Innovative technologies & 5 \\
GPP & 4 \\
\hline
\end{tabular}

EMS Environmental Management Systems, GPP green public procurement 
returned and, even if not complete, the map derived from them is very significant.

The picture that can be derived from this survey is 'black and white' in the sense that there are many positive elements, as the total number of persons involved in LCA, the number of experiences already done, and the well-distributed geographic location of the teams. However, there are also some limits evident, such as the limited involvement in R\&D activities and the international connections.

Figure 1 presents the geographical distribution of LCA teams which, according to their institutional nature, are classified into five classes.

The teams have also been classified according to the number of components. In general, they are small or very small, with only six out 44 consisting of more than ten members.

Most of the teams are involved in executing LCA studies and on providing certification support, with a minority that is working in methodology, R\&D and/or in software tool development.

Table 1 provides the number of active teams in each specialisation area, classified by LCA application and IPP tools. The overall number is greater that 44 , as each team can be active in more that one area.

Only slightly over $50 \%$ of the teams have international co-operations or participate in international projects $(24 / 44$ and another 24/44, respectively; ENEA 2008)

\section{LCA network working groups}

The working groups based on voluntary contribution have the mission to contribute on dissemination and development of LCA methodology in a specific application field.

Currently, six working groups are active in the following application areas:

1. Food and agro-industrial-coordinator, Professor Bruno Notarnicola, University of Bari

2. Technology Assessment - coordinator, Professor Maurizio Cellura, University of Palermo

3. Chemicals - coordinator, Professor Michele Aresta, University of Bari

4. Tourist services - coordinator, Professor Andrea Raggi, University of Pescara

5. Buildings and their thermal plants-coordinators, Dr. Monica Lavagna, University of Milan, and Professor Umberto Desideri, University of Perugia

6. Waste management-coordinator, Professor Antonio Scipioni, University of Padova
The Second LCA Italian Workshop took place in the University of Pescara on 13 March 2008. During the workshop, the working groups' activities were presented, defining the state of art in their application field, identifying the main issues and future activities needed.

The workshop discussion highlighted many issues, among them: the scarce awareness of LCA in Italy involving firms and public administrations and the problem of reliable sector LCI data. Furthermore, several methodological issues concerning the definition of system boundaries and functional unit, the integration of LCA with other methodologies to solve some spatial and temporal problems and the inclusions of economic and social aspects were discussed (Cappellaro and Scalbi 2008). The Second Workshop was a great success for the LCA Italian Network. The participants were made up of 124 individuals, 56 academics, 20 researchers, nine consultants, two firm environmental managers, eight Environmental Protection Agency employees and 29 students.

\section{Conclusions}

Notwithstanding that the participation and contribution to the working groups (and in general to the Network) is on a voluntary basis, the participation is still increasing. Moreover, new events and activities are planned. A third workshop is planned in November, in coincidence with the large trade fair 'Ecomondo', to promote the network to firms and public administrations. The working groups are now developing practical sector, technical guidelines to support firms in the start phase of their product ecoinnovation process.

The Italian LCA network, with its strong vitality, is willing to play a more and more active role to foster the application of LCA in Italy.

\section{References}

Cappellaro F, Scalbi S (2008) 2nd Workshop della Rete Italiana LCA: "Sviluppi dell'LCA in Italia - percorsi a confronto", Proceedings. Edited by ENEA, ISBN 88-8286-158-9

Curran MA, Notten P (2006) Summary of global life cycle inventory data resources, Task Force 1: Database Registry. SETAC/UNEP Life Cycle Initiative

ENEA ACS-PROT_INN "LCA and Ecodesign Group" (2008) Seconda mappatura nazionale dei gruppi e delle attività nel campo dell'analisi del ciclo di vita (LCA). Edited by ENEA 